\title{
Sturge-Weber Syndrome. Study of 55 Patients
}

\author{
Ignacio Pascual-Castroviejo, Samuel-Ignacio Pascual-Pascual, \\ Ramón Velazquez-Fragua, Juán Viaño
}

\begin{abstract}
Purpose: To review the clinical and neuroimaging features of a large series of patients with Sturge-Weber syndrome (SWS) seen over a 40-year period. Methods: Fifty-five patients with SWS (30 males and 25 females), were studied between 1965 and 2004. Results of neurological and ophthalmological examinations, electroencephalographic, and neuroimaging studies were reviewed. All patients were seen by one of the authors (I. P-C). Results: Epilepsy, hemiparesis, mental retardation and ocular problems were the most frequent and severe features of patients with Sturge-Weber syndrome in this series. The facial nevus flammeus was unilateral in $35(63.5 \%)$ patients, bilateral in $17(31 \%)$ and absent in $3(5.5 \%)$ of the patients with leptomeningeal angiomas. Seven (41\%) of the 17 patients with bilateral nevus flammeus had unilateral leptomeningeal angiomas. Seizures occurred in 47 patients (85.5\%). Complete seizure control was obtained in 20 patients (42.5\%), but in 2 of these 20 patients seizures were controlled only after lobectomy. All patients with unilateral or bilateral upper eyelid nevus flammeus had ipsilateral, unilateral or bilateral choroid-retinal angiomas. Only $20(36 \%)$ of the 55 patients had low-normal or borderline intelligence (IQs $<70)$. No relationship was observed between the size of the facial nevus flammeus and the severity of the brain lesion. Conclusions: Epilepsy, hemiparesis, mental retardation and ocular problems were the most frequent and severe features of patients with Sturge-Weber syndrome in this series. Cerebral lesions followed a progressive course during early childhood, but not later. Early surgical treatment controlled the seizures but other neurological problems such as hemiparesis and intellectual deficits showed a less satisfactory response. Early onset of seizures and poor response to medical treatment, bilateral cerebral involvement and unilateral severe lesions were indicative of a poor prognosis. Limited intelligence and social skills, poor aesthetic appearance and seizures complicated the integration of SWS patients. These features must be addressed in order for the patients improve social interactions, obtain gainful employment and achieve a better quality of life.
\end{abstract}

RÉSUMÉ: Syndrome de Sturge-Weber : Étude de 55 patients. Objectif : Il s'agit d'une revue des manifestations cliniques et de neuroimagerie observées chez une grande série de patients atteints du syndrome de Sturge-Weber (SSW) examinés au cours d'une période de 40 ans. Méthodes : Cinquante-cinq patients atteints du SSW (30 hommes et 25 femmes), ont été examinés entre 1965 et 2004 . Nous revoyons les résultats des examens neurologiques et ophtalmologiques, des études électroencéphalographiques et de neuroimagerie. Tous les patients ont été examinés par un des auteurs (I.P - C). Résultats : Les manifestations les plus fréquentes et les plus sévères chez les patients atteints du SSW dans cette série de cas étaient l'épilepsie, l'hémiparésie, le retard mental et les problèmes oculaires. Le naevus flammeus facial était unilatéral chez 35 patients (63,5\%) atteints d'angiomes des leptoméninges, bilatéral chez 17 patients (31\%) et absent chez 3 patients (5,5\%). Sept patients (41\%) parmi les 17 patients atteints de naevus flammeus bilatéral avaient des angiomes leptoméningés unilatéraux. Quarante-sept patients $(85,5 \%)$ présentaient des crises convulsives. Un contrôle absolu des crises a été obtenu chez 20 patients $(42,5 \%)$. Cependant, chez 2 de ces patients les crises ont été contrôlées seulement après une lobectomie. Tous les patients porteurs de naevus flammeus unilatéral ou bilatéral de la paupière supérieure avaient des angiomes choroïdo-rétiniens ipsilatéraux, unilatéraux ou bilatéraux. Seulement 20 des 55 patients $(36 \%)$ avaient une intelligence normale basse ou limite $(\mathrm{QI}<70)$. Aucune relation n'a été observée entre la taille des naevi faciaux et la sévérité des lésions cérébrales. Conclusions : L'épilepsie, l'hémiparésie, le retard mental et les problèmes oculaires étaient les manifestations les plus fréquentes et les plus sévères du SSW chez les patients de cette série. Les lésions cérébrales progressaient tôt dans l'enfance, mais elle ne progressaient pas par la suite. Un traitement chirurgical précoce a permis de contrôler les crises convulsives mais les résultats étaient mitigés en ce qui concerne les autres problèmes neurologiques comme l'hémiparésie et les déficits intellectuels. Un début précoce des crises convulsives, une réponse mitigée au traitement, des lésions cérébrales bilatérales et des lésions sévères unilatérales étaient associées à un pronostic défavorable. Une intelligence et des habiletés sociales limitées, une apparence peu esthétique et des crises convulsives compromettaient l'intégration des patients atteints de SSW. Ces problèmes doivent être abordés afin d'améliorer les interactions sociales et la qualité de vie des patients et de favoriser leur accès à un emploi rémunérateur.

Can. J. Neurol. Sci. 2008; 35: 301-307

From the Pediatric Neurology Service (I P-C, S-IP-P, R V-F), University Hospital La Paz; Image Unit (JV), Nuestra Señora del Rosario Clinic, Madrid, Spain.

Received May 1, 2007. Final Revisions Submitted December 21, 2007.

Reprint requests to: I. Pascual-Castroviejo, 14 Orense Street, Madrid, 28020, Spain. 
Sturge-Weber syndrome (SWS) is a neurocutaneous disorder characterized by ${ }^{1}$ : a) cutaneous nevus flammeus that affects the facial area innervated by the first sensory branch of the trigeminal nerve; b) ipsilateral leptomeningeal angioma and, in many cases, of retinal choroidal angioma; c) seizures (mostly partial); d) hemiparesis or hemiplegia contralateral to the side of the leptomeningeal angiomatosis; and e) mental retardation. Some patients are accepted as having SWS when they have typical neurological features and leptomeningeal angioma, but lack a facial nevus flammeus. ${ }^{2}$

We describe in this paper the clinical and neuroimaging findings in a personal series of 55 patients with SWS, most of whom were followed for many years (in some cases up to 30 years).

\section{Patients And Methods}

Fifty-five SWS patients (30 males, 25 females) were studied in the Pediatric Neurology Service of the University Hospital La Paz (Madrid, Spain) from August 1965 to May 2004. Forty of these patients have been reported previously, ${ }^{1}$ and one who did not show facial nevus flammeus was described in another publication. $^{2}$

The age of the patients at diagnosis ranged from newborn (eight patients were studied during the neonatal period) to 12 years of age ( mean: 24 months). Facial nevus locations are listed in Table 1.

Inclusion criteria of the patients were: 1) the presence of unilateral or bilateral facial nevus flammeus distributed over a partial or total zone innervated by the first sensory branch of the trigeminal nerve; 2) neuroimaging evidence of hemispheric cerebral disease ipsilateral to the facial nevus flammeus; and 3) presence of an occipital leptomeningeal angioma in MRI enhanced with gadolinium-DTPA (Gd-DTPA) or demonstration by SPECT of decreased perfusion in the subjacent cerebral region to the leptomeningeal angioma in children with focal seizures without facial nevus flammeus.
Specific protocol used to study these patients consisted of clinical, electroencephalographic (EEG), ophthalmologic, and neuroimaging studies. All patients seen between 1974 and 1986 were studied by computed tomography (CT). Some of those who were followed before 1974 had been studied with skull radiographs, pneumoencephalography and carotid arteriography, but later, when they came to the hospital for follow-up, were studied by CT. Since 1987, all 35 patients examined were studied with MRI enhanced with Gd-DTPA and MR angiography (MRA), with special attention to the venous system. Seven patients were studied with SPECT (the three without facial nevus flammeus who showed small size leptomeningeal angiomas, and four other patients with facial nevus flammeus and larger leptomeningeal angiomas). Follow-up protocol of patients varied according to the age of the patient, severity of the disease and resistance of the seizures to medication. Clinical examinations were performed frequently during the first and the second years of life in children with numerous seizures. An EEG was also frequently performed if the type of seizures changed or the response to the medication was poor. Magnetic resonance imaging enhanced with Gd-DTPA and MRA were repeated at six and 12 months after the first study, especially in children below one year of age in whom the disease showed a progressive deterioration and surgical treatment was considered as a possibility.

After two or three years of age, clinical and EEG examinations were made yearly and MRI with Gd-DTPA every three to ten years (according to the clinical situation). Intelligence levels were measured in most patients using the Weschsler Intelligence Scale for Children (WISC or WISC-R) for Adults (WAIS), according to age.

Laser therapy was applied to the facial nevus flammeus in 12 patients between 1989 and 2000, but most patients discontinued this treatment because of poor results.

Table 1: Location of the facial nevus flammeus skin-sensory zones of the trigeminal branches

\begin{tabular}{|c|c|c|c|c|}
\hline Unilateral & 1st & 1st, 2nd & 1st, 2nd, 3rd & Patients \\
\hline Left & 5 & 15 & 1 & 21 \\
\hline Right & 4 & 4 & 6 & 14 \\
\hline Total & & & & $35(63.5 \%)$ \\
\hline \multicolumn{5}{|l|}{ Bilateral } \\
\hline Three branches of both sides & & & & 14 \\
\hline Three branches of the left side plus 1 st of right side & & & & 2 \\
\hline Three branches of the right side plus 1 st of left side & & & & 1 \\
\hline Total & & & & $17(31.0 \%)$ \\
\hline \multirow[t]{2}{*}{ No facial nevus flammeus } & & & & $3(5.5 \%)$ \\
\hline & & & & Total $55(100 \%)$ \\
\hline
\end{tabular}




\section{RESULTS}

\section{Nevus flammeus}

The location of facial nevus flammeus is shown in Table 1. Seven of the 17 patients with bilateral cutaneous nevus flammeus had bilateral cerebral lesions, although a disproportionately larger abnormality in one of the hemispheres could be observed in six of the seven patients. The other ten patients with bilateral cutaneous lesion showed cerebral leptomeningeal angioma only on one side. Neither the size or color, nor unilateral or bilateral location of the nevus, had any influence on disease severity.

\section{Seizures}

Forty-seven patients (85.5\%) suffered seizures and these were treated with antiepileptic medication. Thirty-four (72\%) had partial seizures contralateral to the facial nevus, but later eight $(23 \%)$ of these patients developed generalized tonic-clonic or myoclonic seizures, or both. Ten patients $(21 \%)$ had the onset of epileptic manifestations with generalized tonic-clonic seizures, although later at least $50 \%$ of them also had partial seizures. Three patients $(7 \%)$ initially had infantile spasms. All these patients later developed both partial and generalized tonic-clonic seizures. Mean seizures onset was at eight months (range: birth to six years). Thirty-six (75\%) children had the first seizure during the first year, eight (18\%) between the first and the second year and three $(7 \%)$ between two and six years of age. The seizures began during febrile episodes in 13 patients $(30 \%)$. Both high and low-grade fevers could also trigger subsequent seizures at any time in most patients. During the first and second years of age, the seizures (partial, generalized tonic-clonic or partial with secondary generalization) were markedly resistant to medical treatment. Beginning with the second or third year of age, seizures most frequently were of partial simple type and these appeared to respond better to antiepileptic drugs. From adolescence onward, complex partial seizures without complete loss of consciousness were seen most frequently. The main antiepileptic drugs used were carbamazepine, phenytoin, valproic acid and, in recent years, levetiracetam. The later has been one the most effective drugs in the control of seizures in the patients in this series. Patients having more severe epilepsy had an earlier onset of seizures.

Satisfactory seizure control was obtained in 20 patients $(42.5 \%)$ but in two of these with neonatal presentation of epilepsy, control was possible only after frontal lobectomy was performed during the first year of life. These were the only patients operated upon because of seizures.

\section{EEG}

The EEG was considered to be normal in 11 patients (eight with no seizures and three with a few partial seizures coinciding with febrile episodes). Asymmetric voltage was observed in most patients, with low-voltage ipsilateral to the affected hemisphere. Ipsilateral focal paroxysmal discharges in the low-voltage EEG was observed in 15 patients, and contralateral focal paroxysmal discharges in seven. Isolated contralateral focal paroxysms occurred in four patients and hypsarrhythmia in three. Six of the seven patients with bilateral leptomeningeal angiomas showed a greater severity in one hemisphere, with predominance of the low-voltage focal discharges in the ipsilateral hemisphere. Electroencephalographic abnormalities improved with age and, in adults, the asymmetric voltage was difficult to see in most patients, especially if cerebral hemiatrophy was not severe. Motor impairment of high, middle or low severity with myotactic hyperreflexia on the contralateral side to the cerebral lesion, was observed in almost all 55 SWS patients. The EEG abnormality was seen from the first few months of life. Patients with less severe cerebral lesions showed only a discrete motor clumsiness that made utilization of the affected hand more difficult compared to the other hand. Severity of motor disease was related to the extent of the cerebral lesion and also with the refractoriness of the seizures to antiepileptic medication. Headache was mentioned only by adults, but not spontaneously.

\section{Mental Retardation}

Mental development was followed during a prolonged time in most patients and some of them even surpassed 40 years of age. Intellectual development of the patients is listed in Table 2. None of the patients achieved superior or middle schooling even among those with complete or almost complete seizure control and normal or borderline mental levels who tended to improve during adulthood. Intellectual level was related to the age at onset of seizures, a poor response to the medication and the severity of the cerebral lesion that could be bilateral or unilateral. Early onset and refractory seizures to the medication were associated with a lower mental level and more severe motor impairment. Emotional and behavioural problems that corresponded to attention deficit/hyperactivity disorder (ADHD) were observed in $23(42 \%)$ of the patients.

\section{Neuroimaging Studies}

Computed tomogram and magnetic resonance imaging documented the increase in density or signal of the cerebral lesion located in the zone subjacent to the leptomeningeal angioma as well as the appearance of cortico-subcortical atrophy affecting a lobe or the complete hemisphere, revealing a progressive character in all patients. Two patients with prenatal onset of the disease showed cortico-subcortical calcifications

Table 2: Intellectual development

\begin{tabular}{lcc}
\hline IQ & Patients & Percentage \\
Normal (IQ>85) & 14 & 25 \\
Borderline (IQ 70-85) & 6 & 11 \\
Discrete retardation (IQ 55-70) & 6 & 11 \\
Moderate retardation (IQ 40-55) & 6 & 11 \\
Severe retardation (IQ<40) & 11 & 20 \\
Not tested & 12 & 22 \\
Total & 55 & 100 \\
\hline
\end{tabular}




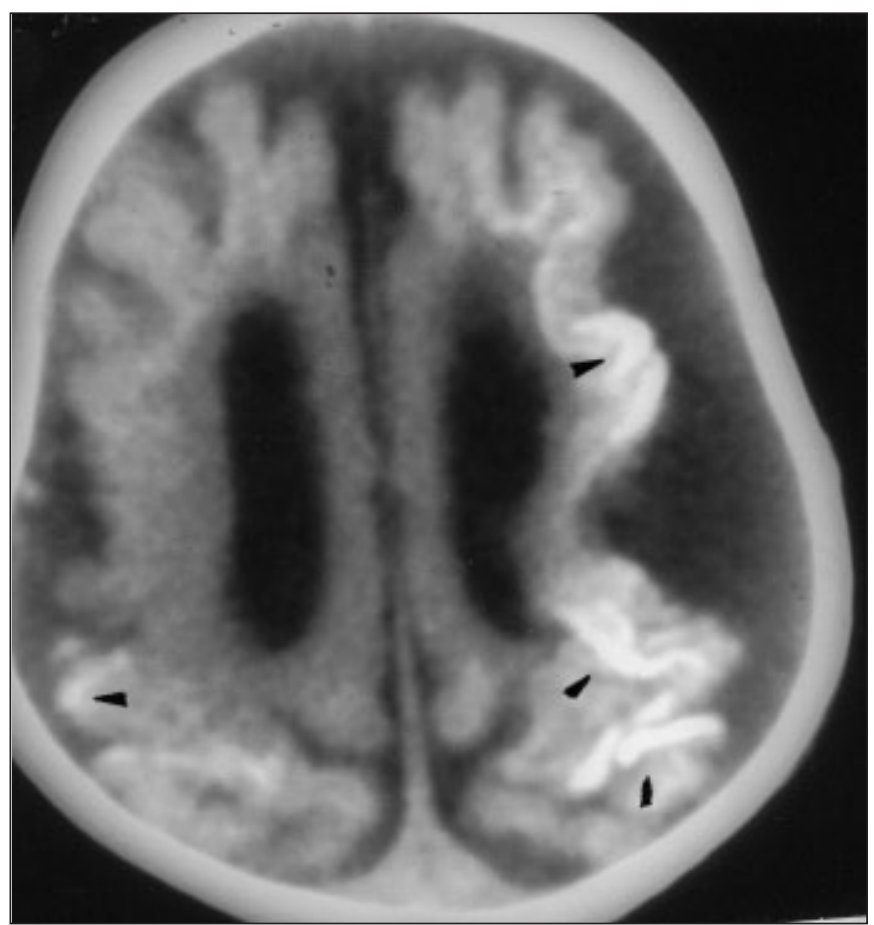

Figure 1: MRI of a newborn with SWS. Axial view shows severe bilateral cerebral atrophy, parenchymal hypersignal zones (arrowheads) and lateral ventricular enlargement.

and dysplasia of the cerebral cortex at birth (Figure 1). Magnetic resonance imaging enhanced with Gd-DTPA demonstrated leptomeningeal angioma in all patients. Seven of the 17 patients with bilateral facial nevus flammeus also had bilateral leptomeningeal angiomas and cerebral lesions, although parenchymal involvement predominated in one hemisphere in six of the seven patients. Leptomeningeal angioma in the cerebellar hemisphere ipsilateral to the affected cerebral hemisphere was seen in only one patient in this series who showed nevus flammeus affecting the facial distribution innervated by the three sensory trigeminal branches and the ipsilateral neck. The cerebral hemisphere was atrophic and the cerebellar hemisphere showed hypertrophy (Figure 2). SPECT showed hypoperfusion of the subjacent area of the leptomeningeal angioma in all seven patients studied by this method. Arteriography or MRA was performed in 43 patients, demonstrating smaller-sized intracranial arteries secondary to cerebral atrophy in the affected hemisphere in patients over twoyears of age. A lack of superficial veins, associated non-filling of the superior sagittal sinus, thickening and tortuosity of the deep subependymal and medullary veins and, in some patients, bizarre course of the cerebral veins were observed. Some of these anomalies appeared in one or both hemispheres in accordance with the unilaterality or bilaterality of the leptomeningeal hemangioma (Figure 3) in most patients.

\section{Ocular Disease}

Glaucoma was the main ocular disease observed in 41 patients $(74.5 \%)$. It was unilateral in $27(66 \%)$ and bilateral in 14 (34\%). Glaucoma was related to the extension of the nevus flammeus in the palpebral area. Patients with SWS who had a nevus flammeus not involving the palpebral area did not develop glaucoma or choroidal angioma. Age at onset (known for most patients) was during the first year of life in $36(87.8 \%)$ patients (in $18(42.5 \%)$ from birth) and between one and eight years in five $(12.2 \%)$ patients. Follow-up with frequent ophthalmological examinations and various medical and surgical treatments did not prevent an important loss of visual acuity in most patients. Reliable testing of the visual fields to demonstrate all the possible defects, especially hemianopsia, was very difficult

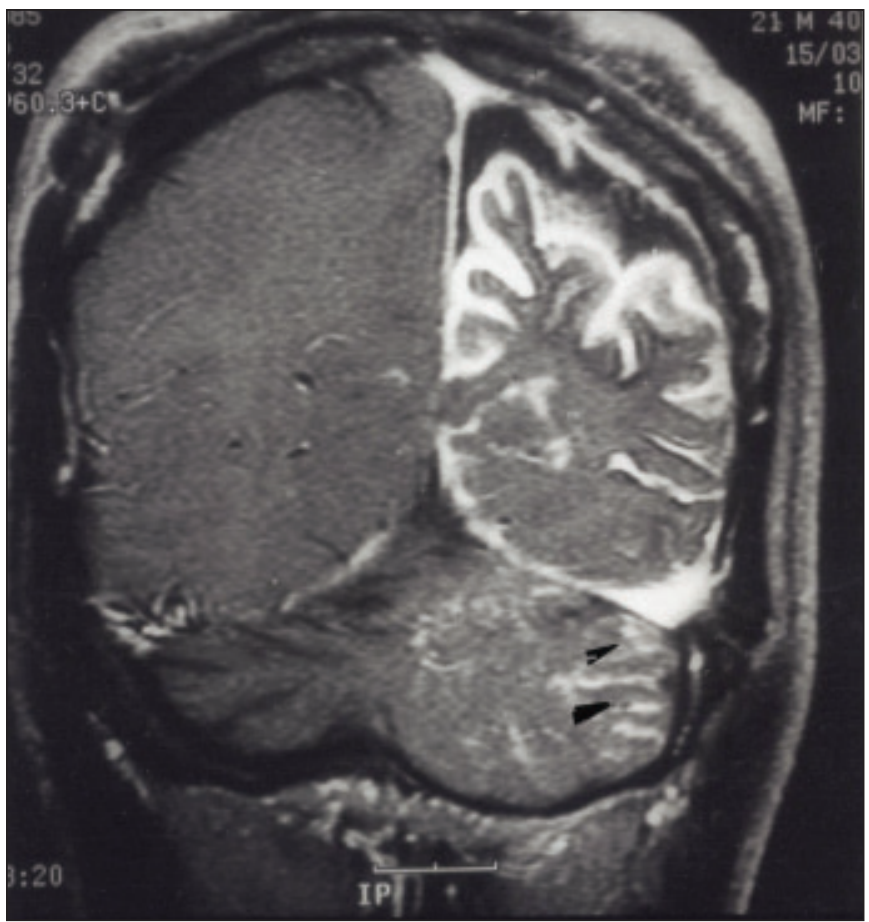

Figure 2: Coronal view of the MRI enhanced with Gd-DTPA of a 16year-old patient shows leptomeningeal angioma, hemiatrophy of the left cerebral hemisphere, and leptomeningeal angioma (arrowheads) and hypertrophy of the left cerebellar hemisphere.

because of many problems, such as young ages and low IQs of many of the patients, and we did not evaluate this any further. The MRI with GD-DTPA also demonstrated choroidal angiomas in all patients with facial nevus flammeus extending to the upper eyelid, being unilateral or bilatelral in accordance with the unilaterality or bilaterality of the palpebral nevus flammeus. 


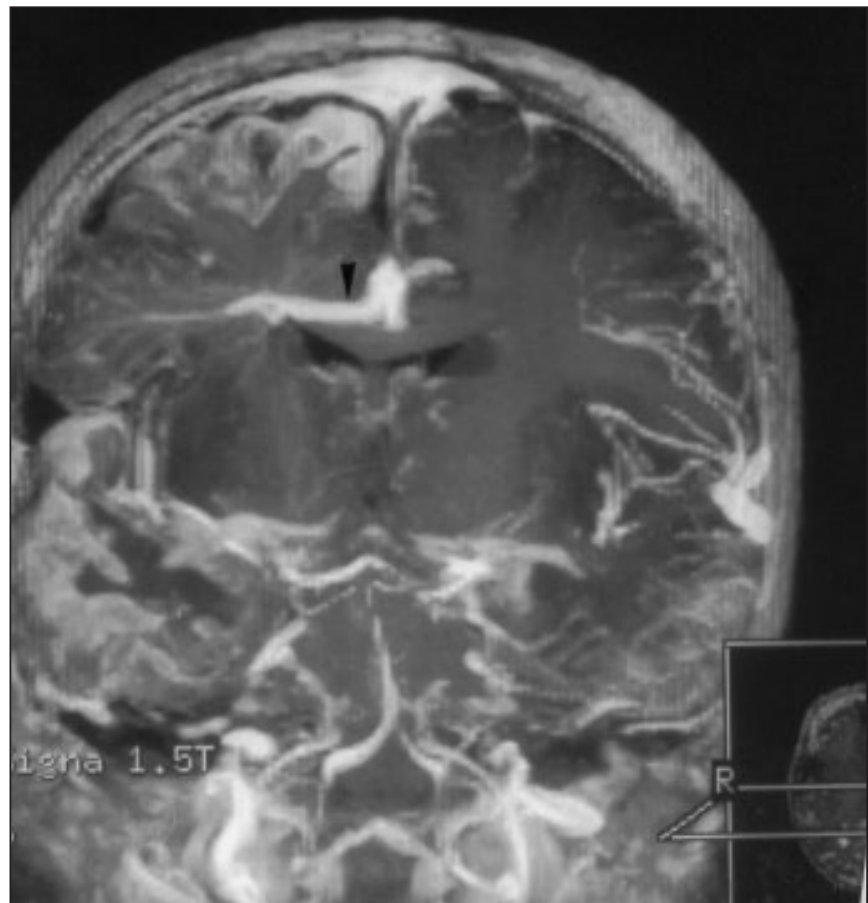

Figure 3: MRA in a 28-year-old patient. The coronal view shows almost complete absence of superficial veins in the right cerebral hemisphere and thickening of a deep vein that drains into the longitudinal venous sinus (arrowhead). The venous system appears normal in the left hemisphere.

Patients with nevus flammeus extending to the upper eyelid on both sides showed choroidal hemangioma in both eyes despite having leptomeningeal angioma in only one side. Three patients (one child, one adolescent and one adult) with choroidal angioma, developed retinal hemorrhages (Figure 4).

\section{DisCuSSION}

Sturge-Weber syndrome commonly manifests initially with the cutaneous lesion, a nevus flammeus that affects the facial area innervated by the first sensory branch of the trigeminal nerve. Five patients without facial nevus were noted in a review of 35 patients $^{3}$ and, in the present series, there were 3 of 55 patients without facial nevus. Leptomeningeal angioma may be located not only in the typical occipital area, but also in other locations in patients with and without facial nevus flammeus. ${ }^{4}$

Central nervous system (CNS) features commonly consist of seizures, neurological deficit (especially hemiparesis or hemiplegia), decreased mental level and behavioural problems. Seizures are one of the main CNS features of SWS patients. Convulsions have been reported in $62 \%,{ }^{5} 80 \%,{ }^{1} 83 \%{ }^{6}$ and $89 \%{ }^{3}$ of patients with SWS. In the present series, 47 of the 55 patients $(85.5 \%)$ had seizures, most commonly partial motor at onset. Partial and generalized tonic-clonic or myoclonic seizures occur with febrile episodes in about a third of patients with SWS. ${ }^{1}$

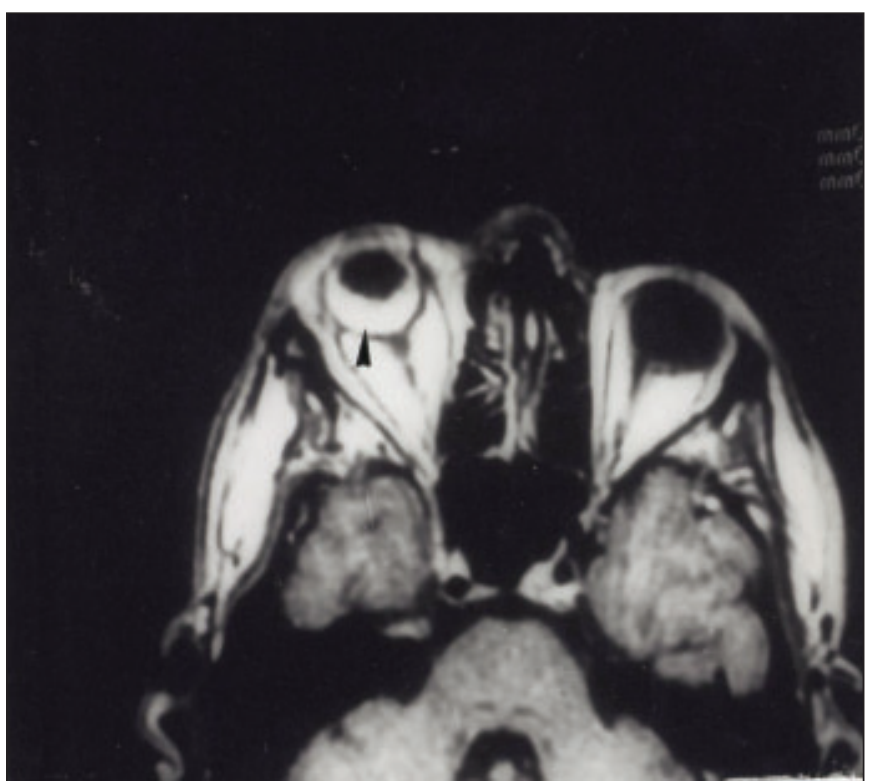

Figure 4: Axial view of the MRI enhanced with Gd-DTPA in a 24-yearold patient shows retinal hemorrhage in the right eye (arrowhead).

Fever can also trigger subsequent seizures at any age. Seizures start before the age of one in $75 \%$ of patients with epilepsy. ${ }^{6}$ The mean age of seizures onset was eight months in this series (range birth to six years) starting during the first year in 37 patients (75\%). In other series reporting only adults ${ }^{6} 12 \%$ of patients did not develop seizures until the third decade of the life. ${ }^{6}$ Despite adequate treatment of seizures with antiepileptic drugs, seizure control is achieved in less than $50 \%$ of patients. ${ }^{1}$ Most SWS patients are treated for epilepsy starting at a very early age, and remain on antiepileptic medications for life. In patients whose seizures are difficult to control and who also have mental retardation and permanent paralysis, neurosurgical procedures such as lobectomy ${ }^{7,8}$ or hemispherectomy ${ }^{9}$ appear to be the best options. Any of these procedures should be considered early on during the first year of life. ${ }^{10-12}$ Early periinsular hemispherectomy may be an effective and comparatively safe surgical technique in drug-resistant epilepsies with wide-spread hemispheric angioma. ${ }^{13}$ Surgical treatment can be successful with functional hemispherectomy in patients with bilateral SWS in whom clinical examination and neurophysiological studies with ictal video recording demonstrate epileptogenesis from only one hemisphere. ${ }^{14}$ The worst prognosis is observed in patients with bilateral cerebral lesions and in those with unilateral lesions in whom the entire hemisphere is severely involved, such as was observed in the present series. On the contrary, no relationship appears to exist between the facial nevus flammeus extension or its unilateral or bilateral location and the clinical neurological impairment. ${ }^{1,15}$ Headaches are a greater problem in SWS patients 
with a median age over 18 years. ${ }^{16}$ Adult SWS patients often complain of headaches, but children seldom do.

The prevalent EEG finding is asymmetry of the background amplitude during the waking record, usually involving the entire affected hemisphere ${ }^{17}$ that can be seen from the first months of life. This is more noticeable as cerebral hemiatrophy becomes more severe during the first years of life, but the asymmetry decreases thereafter. Focal paroxysms mainly occur in the affected cerebral hemisphere.

Sequential examinations of SWS patients show progressive cerebral cortical-subcortical atrophy, especially during the first years of life. These changes can be documented by CT and MRI, ${ }^{1,15,18}$ and often appear in the neonate. ${ }^{19-21}$ These abnormalities have a vascular origin ${ }^{19,22}$ and may be due to changes in the vessel permeability and stasis in the vascular lumen which cause anoxic lesions in the endothelium. Some patients may have acute episodes of intracranial hypertension probably caused by impairment of cerebral venous outflow. ${ }^{23}$ Perfusion MRI shows early changes compatible with impaired venous drainage in the affected hemisphere. ${ }^{15}$ Magnetic resonance imaging studies demonstrate cerebral lesions on both the T1- and T2-weighted images. Enhancement of MRI with GdDTPA has become an indispensable study tool because it shows not only the presence of leptomeningeal angioma but also the extension into one or both cerebral hemispheres, choroid plexus, cerebellar hemispheres, and the eyes. ${ }^{1,24,25}$

A pattern of accelerated myelination in the cerebral hemisphere has been reported in young children. ${ }^{25,26}$ Vascular changes that affected arteries and veins have been seldom documented. ${ }^{1,27,28}$ Such vascular abnormalities appear to affect more severely the venous than the arterial system.

SPECT and PET studies in symptomatic children have demonstrated decreased perfusion and glucose metabolism in the affected cerebral hemisphere. ${ }^{2,29}$ Quantitative MRI volumetry and PET studies show that the grey-matter volume ipsilateral to the angiomas is smaller in all children with SWS, with the posterior regions underneath the leptomeningeal angioma being the most affected. ${ }^{29}$ Quantitative analysis using a computer-aided analysis of MRI may show laterality scores for cortical volume asymmetry that correlates with clinical status. ${ }^{30}$

Mental retardation has been reported in $60 \%$ of 40 children with SWS, ${ }^{1}$ in $55 \%$ of 52 adults, ${ }^{6}$ in $54 \%$ of 35 patients of all ages, ${ }^{3}$ in $46 \%$ of patients with unihemispheric lesions and in $84 \%$ with bihemispheric lesions in a series of 102 patients of SWS who were seen at the Mayo Clinic between 1942 and 1986. ${ }^{5}$

Many patients with SWS present with attention deficit/ hyperactivity disorder (ADHD). Chapieski et al ${ }^{17}$ reported $22 \%$ in a series of 79 children and adolescents. The prevalence of ADHD was higher (about $42 \%$ ) in our series.

The main eye diseases consisted of glaucoma, visual loss, strabismus and retinal lesions. Choroidal retinal and leptomeningeal angiomas are only demonstrable using MRI enhanced with Gd-DTPA ${ }^{1,25}$ and these are usually present since birth. Patients who showed unilateral palpebral angioma affecting the upper eyelid have choroidal angioma only in the ipsilateral eye, and patients who showed palpebral angioma on both sides also have retinal angiomas in both eyes. Hemorrhages of the retina are also observed in some patients with SWS, most commonly in adults. Glaucoma is associated with nevus involving both the upper and lower lids. ${ }^{3}$ Glaucoma with a choroidal angioma occurs in about the $60 \%,{ }^{6}$ and requires close ophthalmologic follow-up.

The origin and pathophysiology of SWS remain poorly understood. The chronic state of reduced perfusion demonstrated by PET studies and the impaired venous drainage of the cortex underlying the angioma observed in SWS, ${ }^{15}$ suggest the possibility that the lack of normal cortical veins interacting with the overlying angioma produces thrombosis and stasis, resulting in ischemia of cortical tissue. Decreased fibronectin expression in SWS meningeal vessels and increased fibronectin in the parenchymal vessels could contribute to abnormal vascular structure and function in this disorder. ${ }^{31}$ Sturge-Weber syndrome likely results from an early embryologic malformation of vascular development affecting the adjacent skin, eye, and brain structure. $^{32}$

Almost $50 \%$ of adults with SWS are able to work in regular or in protected work environment and are already married or eligible to be married. ${ }^{6}$ However, the presence of seizures, problems of intelligence and/or behaviour, depression, motor or sensory handicaps, visual problems, low self-esteem, and poor motivation to work, decrease their chances to live independently. Many patients with SWS, including those in this series, need some type of protection or assistance to incorporate themselves effectively into society and live according to their potential.

\section{REFERENCES}

1. Pascual-Castroviejo I, Díaz-Gonzalez C, García-Melián RM, Gonzalez-Casado I, Muñoz-Hiraldo E. Sturge-Weber syndrome: Study of 40 patients. Pediatric Neurol. 1993; 9 (4): 283-8.

2. Pascual-Castroviejo I, Pascual-Pascual SI, Viaño J, Martinez V, Coya J. Sturge-Weber syndrome without facial nevus. Neuropediatrics. 1995; 26 (4): 220-2.

3. Peterman AF, Hayles AB, Dockerty MB, Love JG. Encephalotrigeminal angiomatosis (Sturge-Weber disease): clinical study of thirty-five cases. JAMA. 1958; 167 (18): 2169-76.

4. Comi AM, Fischer R, Kossoff EH. Encephalofacial angiomatosis sparing the occipital lobe and without facial nevus: on the spectrum of Sturge-Weber syndrome variants? J Child Neurol. 2003; 18 (1): 35-8.

5. Bebin EM, Gomez MR. Prognosis in Sturge-Weber disease: comparison of unihemispheric and bihemispheric involvement. J Child Neurol. 1988; 3 (3): 181-4

6. Sujansky E, Conradi S. Outcome of Sturge-Weber syndrome in 52 adults. Am J Med Genet 1995; 57(1): 35-45.

7. Buttler G, Schulte FJ. Zur operation behandbung des Sturge-Weber syndrome. Neuropediatrie. 1975; 6 (2): 135-41.

8. Rosen I, Salford L. Sturge-Weber disease -neurophysiological evaluation of a case with secondary epileptogenesis, successfully treated with lobe-ectomy. Neuropediatrics. 1984; 15 (2): 95-8.

9. Hoffmann HJ, Hendrick EB, Dennis M, Amstrong D. Hemispherectomy for Sturge-Weber syndrome. Childs Brain. 1979; (3): 233-48.

10. Ogunmekan AO, Hwang PA, Hoffmann HJ. Sturge-Weber-Dimitry disease. Role of hemispherectomy in prognosis. Can J Neurol Sci. 1989; 16: (1): 78-80.

11. Arzimanoglou AA, Andermann F, Aicardi J, Sainte-Rose C, Beaulieu MA, Villemure JC, et al. Sturge-Weber syndrome. Indications and results of surgery in 20 patients. Neurology. 2000; 55 (10): 1472-9.

12. Kossoff EH, Buck C, Freeman JM. Outcomes of 32 hemispherectomies for Sturge-Weber syndrome worldwide. Neurology. 2002; 59 (12): 1735-8. 
13. Schropp C, Sörensen N, Krauss J. Early periinsular hemispherectomy in children with Sturge-Weber syndrome and intractable epilepsy-outcome in eight patients. Neuropediatrics. 2006; 37 (1): 26-31.

14. Tuxhorn IEB, Pannek HW. Epilepsy surgery in bilateral SturgeWeber syndrome. Pediatr Neurol. 2002; 26 (5): 394-7.

15. Lin DDM, Barker PB, Kraut MA, Comi A. Early characteristics of Sturge-Weber syndrome shown by perfusion MR imaging and proton MR spectroscopic imaging. Am J Neuroradiol. 1003; 24 (9): 1912-5.

16. Kossoff EH, Hatfield LA, Ball KL, Comi AM. Comorbidity of epilepsy and headache in patients with Sturge-Weber syndrome. J Child Neurol. 2005; 20 (8): 678-82.

17. Chapieski L, Friedman A, Lachar D. Psychological functioning in children and adolescents with Sturge-Weber syndrome. J Child Neurol. 2000; 15 (10): 660-5.

18. Martí-Bonmatí L, Menor F, Poyatos C, Cortina H. Diagnosis of Sturge-Weber syndrome: comparison of the efficacy of CT and MR imaging in 14 cases. AJR Amer J Radiol. 1991; 158 (4): 867 71.

19. Kitahara T, Maki Y. A case of Sturge-Weber disease with epilepsy and intracranial calcification in the neonatal period. Eur Neurol. 1978; 17(1) 8-12.

20. Portilla P, Husson B, Lasjaunias P, Landrieu P. Sturge-Weber disease with repercussion on the prenatal development of the cerebral hemisphere. AJNR Am J Neuroradiol. 2002; 23(3): 490-2.

21. Campistol J, García-Cazorla A, Gonzalez-Campo C. Sturge-Weber disease with unusual cerebral atrophy and hydrocephalus. Eur J Paediatr Neurol. 1999; 3 (5): 227-9.

22. Di Trapani G, Di Rocco C, Abbmonti AL, Calderelli M. Light microscopy and ultrastructural studies of Sturge-Weber disease. Childs Brain. 1982; 9 (1): 23-6.

23. Kiley MA, Oxburg JM, Coley SC. Intracranial hypertension in Sturge-Weber / Klippel-Trenaunay-Weber overlap syndrome due to impairment of cerebral-venous outflow. J Clin Neurosci. 2002; 9 (3): 330-8.
24. Benedikt RA, Brown DC, Walker R, Ghaed UN, Mitchell M, Geyer CA. Sturge-Weber syndrome: cranial MR imaging with GdDTPA. AJNR Am J Neuradiol. 1993; 14 (2): 409-15.

25. Griffiths PD, Boodram MB, Blaser S, Altomare F, Buncic JR, Levin $\mathrm{AV}$, et al. Abnormal ocular enhancement in Sturge-Weber syndrome: correlation of ocular MR and CT findings with clinical and intracranial imaging findings. AJNR Am J Neuroradiol. 1996; 17 (4): 749-54.

26. Jacoby CG, Yuh WTC, Afifi AK, Bell WE, Schelper RL, Sato Y. Accelerated myelination in early Sturge-Weber syndrome demonstrated by MR imaging. J Comp Assist Tomogr. 1987; 11 (2): 226-31.

27. Adamsbaum C, Pinton F, Rolland Y, Chiron C, Dulac O, Kalifa G. Accelerated myelination in early Sturge-Weber syndrome: MRISPECT correlations. Pediatr Radiol. 1996; 26 (11): 759-62.

28. Vogl TJ, Stemmler J, Bergman C, Pfluger T, Egger E, Lissner J. MR and MR angiography of Sturge-Weber syndrome. AJNR Am J Neuroradiol. 1993; 14 (2): 417-25.

29. Lee JS, Asano E, Muzik O, Chugani DC, Juhász C, Pfund Z, et al. Sturge-Weber syndrome. Correlation between clinical course and FDG PET findings. Neurology. 2001; 57 (2): 189-95.

30. Kelley TM, Hatfield LA, Lin DDM, Comi AM. Quantitative analysis of cerebral cortical atrophy and correlation with clinical severity in unilateral Sturge-Weber syndrome. J Child Neurol. 2005; 20 (11): 867-70.

31. Comi AM, Weisz CJC, Highet BH, Skolasky RL, Pardo CA, Hess EJ. Sturge-Weber syndrome: altered blood vessel fibronectin expression and morphology. J Child Neurol. 2005; 20 (7): 572-7.

32. Comi AM. Pathophysiology of Sturge-Weber syndrome. J Child Neurol. 2003; 18 (8): 509-16. 